\title{
Does Prenatal Nicotine Exposure Sensitize the Brain to Nicotine-Induced Neurotoxicity in Adolescence?
}

\author{
Yael Abreu-Villaça ${ }^{1,2}$, Frederic J Seidler' and Theodore A Slotkin*,' \\ 'Department of Pharmacology and Cancer Biology, Duke University Medical Center, Durham, NC, USA; 'Faculdade de Ciências Médicas, \\ Fundação Educacional Serra dos Órgãos (FESO), Teresópolis, Rio de Janeiro, Brazil
}

\begin{abstract}
Offspring of women who smoke during pregnancy are themselves more likely to take up smoking in adolescence. We evaluated neurotoxicant effects of prenatal and adolescent nicotine exposure in developing rats to evaluate whether these contribute to a biological basis for this relationship. Rats were given nicotine or vehicle throughout pregnancy and the offspring then again received nicotine or vehicle during adolescence (postnatal days PN30-47.5); this regimen reproduces the plasma nicotine levels found in smokers. Indices of neural cell number (DNA concentration and content), cell size (protein/DNA ratio), and cell membrane surface area (membrane/total protein) were then evaluated in brain regions during adolescent nicotine administration (PN45) and up to I month post-treatment. By itself, prenatal nicotine administration produced cellular alterations that persisted into adolescence, characterized by net cell losses in the midbrain and to a lesser extent, in the cerebral cortex, with corresponding elevations in the membrane/total protein ratio. The hippocampus showed a unique response, with increased DNA content and regional enlargement. Adolescent nicotine treatment alone had similar, albeit smaller effects, but also showed sex-dependence, with effects on protein biomarkers preferential to females. When animals exposed to nicotine prenatally were then given nicotine in adolescence, the net outcome was worsened, largely representing summation of the two individual effects. Our results indicate that prenatal nicotine exposure alters parameters of cell development lasting into adolescence, where the effects add to those elicited directly by adolescent nicotine; neurotoxicant actions may thus contribute to the association between maternal smoking and subsequent smoking in the offspring.

Neuropsychopharmacology (2004) 29, |440-1450, advance online publication, 24 March 2004; doi: I 0. I 038/sj.npp. I 300443
\end{abstract}

Keywords: adolescence; brain development; cell damage; cerebral cortex; DNA; hippocampus; midbrain; nicotine

\section{INTRODUCTION}

Most smokers begin tobacco use during adolescence (National Institute on Drug Abuse, 1998; Nelson et al, 1995; Pierce and Gilpin, 1996) and recent evidence points to biological differences in the reactivity of the adolescent brain to nicotine that contribute to greater addiction potential (Cheeta et al, 2001; Faraday et al, 2001; Kelley and Middaugh, 1999; Klein, 2001; Slawecki and Ehlers, 2002; Slotkin, 2002; Xu et al, 2001, 2002). Nevertheless, about onefourth of teenagers who begin smoking will not become daily smokers (Centers for Disease Control and Prevention, 1998; National Institute on Drug Abuse, 1998; Nelson et al, 1995) and, although some adolescents show a very rapid onset of dependence, other individuals require more prolonged exposure and higher consumption (DiFranza et al, 2000, 2002a, b). Clearly, one contributory factor to

\footnotetext{
*Correspondence: Dr TA Slotkin, Box 3813 DUMC, Duke University of Medical Center, Durham, NC 277I0, USA, Tel: + I 9196818015 , Fax: + I 919684 8197, E-mail: t.slotkin@duke.edu

Received 15 December 2003; revised 27 January 2004; accepted 12 February 2004

Online publication: 20 February 2004 at http://www.acnp.org/citations/ Npp02200403564/default.pdf
}

susceptibility is parental smoking (Bauman et al, 1990; Chassin et al, 2002; Niaura et al, 2001) and specifically maternal smoking during pregnancy (Cornelius et al, 2000; Kandel et al, 1994; Niaura et al, 2001). In animal models, prenatal nicotine exposure by itself evokes neuroteratogenic changes that result in cognitive and behavioral deficits (Levin and Slotkin, 1998; Roy et al, 1998, 2002; Roy and Sabherwal, 1994, 1998; Slotkin, 1992, 1998, 1999) and the vulnerability of specific brain regions and neural pathways to nicotine-induced damage also extends into adolescence (Abreu-Villaça et al, 2003a-c; Slotkin, 2002; Slotkin et al, 2002; Trauth et al, 2000a-c, 2001; Xu et al, 2001, 2002, 2003). Accordingly, one possibility is that prenatal nicotine exposure might predispose the brain to neural damage elicited by nicotine later in life, during adolescence, thus eliciting lasting neurobehavioral changes. The current study addresses this question.

We used established rat models of nicotine administration that maintain steady-state plasma levels at those found in typical smokers (Levin and Slotkin, 1998; Slotkin, 1992, 1998, 1999, 2002), administering the drug throughout gestation and then for a 2.5-week period in adolescence, with evaluations during adolescent exposure and for up to 1 month after the initiation of withdrawal. To characterize 
neural damage, we conducted measurements of DNA and cell protein fractions. As each neural cell contains only a single nucleus (Winick and Noble, 1965), the DNA content (amount of DNA in each brain region) reflects the total number of cells, and the DNA concentration (DNA per unit tissue weight) reflects the cell packing density (Bell et al, 1987; Slotkin et al, 1984; Winick and Noble, 1965). We also assessed protein subfractions related to cell size and membrane surface area: the ratio of total protein/DNA rises with the enlargement of the cell (Bell et al, 1987; Slotkin et al, 1984) and the relative membrane surface area (ie ratio of membrane protein to total cell protein) increases with the development of neuritic projections or with replacement of large cells (eg neurons) with smaller ones (eg glia).

\section{MATERIALS AND METHODS}

\section{Animals and Nicotine Infusions}

All studies were carried out with the approval of the Duke University Institutional Animal Care and Use Committee, in accordance with the declaration of Helsinki and with the Guide for the Care and Use of Laboratory Animals as adopted and promulgated by the National Institutes of Health. Timed-pregnant Sprague-Dawley rats were shipped on gestational day (GD) 2 by climate-controlled truck (total transit time $<1 \mathrm{~h}$ ), housed individually, and allowed free access to food and water. There were four treatment groups: controls (prenatal vehicle + adolescent vehicle), prenatal nicotine exposure (prenatal nicotine + adolescent vehicle), adolescent nicotine exposure (prenatal vehicle + adolescent nicotine), and those receiving the combined treatment (nicotine both during prenatal development and adolescence). On GD4, before implantation of the embryo in the uterine wall, each animal was quickly anesthetized with ether, a $3 \times 3 \mathrm{~cm}^{2}$ area on the back was shaved, and an incision made to permit s.c. insertion of type 2ML2 Alzet osmotic minipumps. Pumps were prepared with nicotine bitartrate dissolved in bacteriostatic water, to deliver an initial dose rate of $6 \mathrm{mg} / \mathrm{kg}$ of nicotine (calculated as free base) per day. The incision was closed with wound clips and the animals were permitted to recover in their home cages. Control animals were implanted with minipumps containing only the water and an equivalent concentration of sodium bitartrate, adjusted to the same $\mathrm{pH}(6.0)$ as the nicotine bitartrate solution. It should be noted that the pump, marketed as a 2 -week infusion device, actually takes 17.5 days to be exhausted completely (information supplied by the manufacturer) and thus the nicotine infusion terminates during GD21. Maternal plasma nicotine levels achieved with this administration model resemble those seen in heavy smokers $(25-60 \mathrm{ng} / \mathrm{ml})$ as characterized previously (Isaac and Rand, 1972; Levin and Slotkin, 1998; Lichtensteiger et al, 1988; Murrin et al, 1985; Slotkin, 1992, 1998, 1999, 2004). This animal model also resembles the effects of maternal smoking in that fetal nicotine levels exceed those found in maternal plasma (Luck et al, 1985; Sarasin et al, 2003).

Parturition occurred during GD22, which was also taken as postnatal day $(\mathrm{PN}) 0$. After birth, pups were randomized within treatment groups and litter sizes were culled to 10 (five males and five females) to ensure standard nutrition.
Randomization was repeated every few days to distribute differential effects of maternal caretaking equally among all litters; cross-fostering, by itself, has no impact on neurochemical or behavioral effects of nicotine exposure (Ribary and Lichtensteiger, 1989). Animals were weaned on PN21.

On PN30, each animal was implanted with a minipump (Alzet type 1002) as already described, again set to deliver either vehicle or nicotine at an initial dose rate of $6 \mathrm{mg} / \mathrm{kg}$ per day, with the infusion terminating during PN47 (Slotkin, 1998; Trauth et al, 1999, 2000b). The nicotine exposure period thus spans the recognized boundaries of adolescence in the rat, as typified by endocrine, pubertal, and behavioral parameters (Spear, 2000). In the adolescent rat this paradigm produces plasma nicotine levels of $25 \mathrm{ng} /$ $\mathrm{ml}$, similar to that in typical smokers (Lichtensteiger et al, 1988; Trauth et al, 2000b); it produces a transient (10\%) reduction in body weight during treatment, an effect that disappears after termination of the infusion (Abreu-Villaça et al, 2003a; Trauth et al, 1999). Studies were conducted at four time points, one during adolescent nicotine administration ( $\mathrm{PN} 45)$ and three during the withdrawal period (PN50, PN60, and PN75). Animals were decapitated and the cerebral cortex, midbrain, and hippocampus were dissected (Trauth et al, 2000b), frozen in liquid nitrogen, and stored at $-45^{\circ} \mathrm{C}$ until assayed. For each treatment group, 12 animals were examined at each age point, equally divided into males and females.

\section{Tissue Preparation and Assays}

Tissues were thawed and homogenized (Polytron, Brinkmann Instruments, Westbury, NY) in approximately 40 volumes of ice-cold $50 \mathrm{mM}$ Tris $\mathrm{HCl}$ ( $\mathrm{pH} 7.4$ ), and aliquots were withdrawn for measurements of total protein (Smith et al, 1985). To prepare the cell membrane fraction, the homogenates were sedimented at $40000 \times g$ for $10 \mathrm{~min}$ and the supernatant solution was discarded. The membrane pellet was resuspended (Polytron) in the original volume of buffer, resedimented, and the resultant pellet was resuspended in approximately 10 volumes (based on the original weight of the tissue) of the same buffer using a smooth glass homogenizer fitted with a Teflon pestle. Aliquots of this resuspension were then assayed for membrane protein.

The assay for DNA has been described in detail in a previous publication (Trauth et al, 2000b). Briefly, DNA was determined in aliquots of the original tissue homogenate using a modified (Trauth et al, 2000b) fluorescent dyebinding method (Labarca and Piagen, 1980). Tissues were diluted in $100 \mathrm{mM} \mathrm{NaCl}, 1 \mathrm{mM}$ EDTA, and $10 \mathrm{mM}$ Tris $\mathrm{HCl}$ $(\mathrm{pH}$ 7.4) and sonicated for $30 \mathrm{~s}$ (Virsonic Cell Disrupter, Virtis, Gardiner, NY). Hoechst 33258 was added to a final concentration of $0.1 \mu \mathrm{g} / \mathrm{ml}$. Samples were then read in a spectrofluorometer using an excitation wavelength of $356 \mathrm{~nm}$ and an emission wavelength of $458 \mathrm{~nm}$, and were quantitated using standards of purified DNA.

\section{Data Analysis}

To avoid type I statistical errors that might result from repeated testing of the global data set, we first performed a global analysis of variance (ANOVA) (with log-transformed data because of heterogeneous variance) incorporating all 
the variables and measures: prenatal treatment, adolescent treatment, brain region, age, sex, and the four biochemical measures (DNA concentration, DNA content, ratio of total protein/DNA, and ratio of membrane protein/total protein). The four determinations were treated as repeated measures, since each was obtained from the same tissue homogenate. This initial test indicated treatment effects that differed among the different biochemical measures, so data were then examined separately for each measure, again using a multivariate ANOVA (prenatal treatment, adolescent treatment, region, age, and sex). Where appropriate, this was followed by post hoc evaluations of each treatment group compared with the controls, using Fisher's protected least significant difference (FPLSD); however, where treatment effects did not interact with other variables only the main effect was recorded without testing of individual differences. Effects of nicotine on body weights were conducted similarly with a multivariate ANOVA (prenatal treatment, adolescent treatment, age, and sex) using log-transformed values; brain region weights were evaluated with the additional factor of region. Significance was assumed at the level of $p<0.05$ for main effects; however, for interactions at $p<0.1$, we also examined whether lowerorder main effects were detectable after subdivision of the interactive variables (Snedecor and Cochran, 1967). All statistical tests were two-tailed.

The study design required two different ways of regarding treatment variables. To compare the effects of prenatal exposure alone, adolescent exposure, or the combined exposure to controls or to each other, the four treatment groups were considered as a one-dimensional factor in the statistical design. To determine whether the effects of prenatal exposure and adolescent exposure were interactive, the treatment factors were changed to a two-dimensional design. In this formulation, more-than-additive (synergistic) and less-than-additive effects appear as significant interactions between the two treatment dimensions, whereas simple, additive effects do not show significant interactions.

Data are presented as means and standard errors. To facilitate comparisons across multiple tissues, ages, and variables, the effects of each treatment are given as the percentage change from the corresponding control group, but statistical comparisons were made on the original data. For reference, control values appear in Table 1.

\section{Materials}

Animals were purchased from Charles River Laboratories (Raleigh, NC) and osmotic minipumps from Durect Corp. (Cupertino, CA). Bacteriostatic water was obtained from Abbott Laboratories (N Chicago, IL). Sigma Chemical Co. (St Louis, MO) was the source for all other reagents.

\section{RESULTS}

Across all four age points, prenatal nicotine exposure did not elicit any significant reductions in body weight, but as in previous studies (Trauth et al, 1999, 2000b), adolescent nicotine reduced weights slightly during the treatment period $\left(<10 \%, \mathrm{~F}_{1,92}=7.7, p<0.007\right)$, with a rapid return to normal upon discontinuing nicotine (data not shown). Prenatal nicotine exposure did not alter the subsequent

Table I Control Values

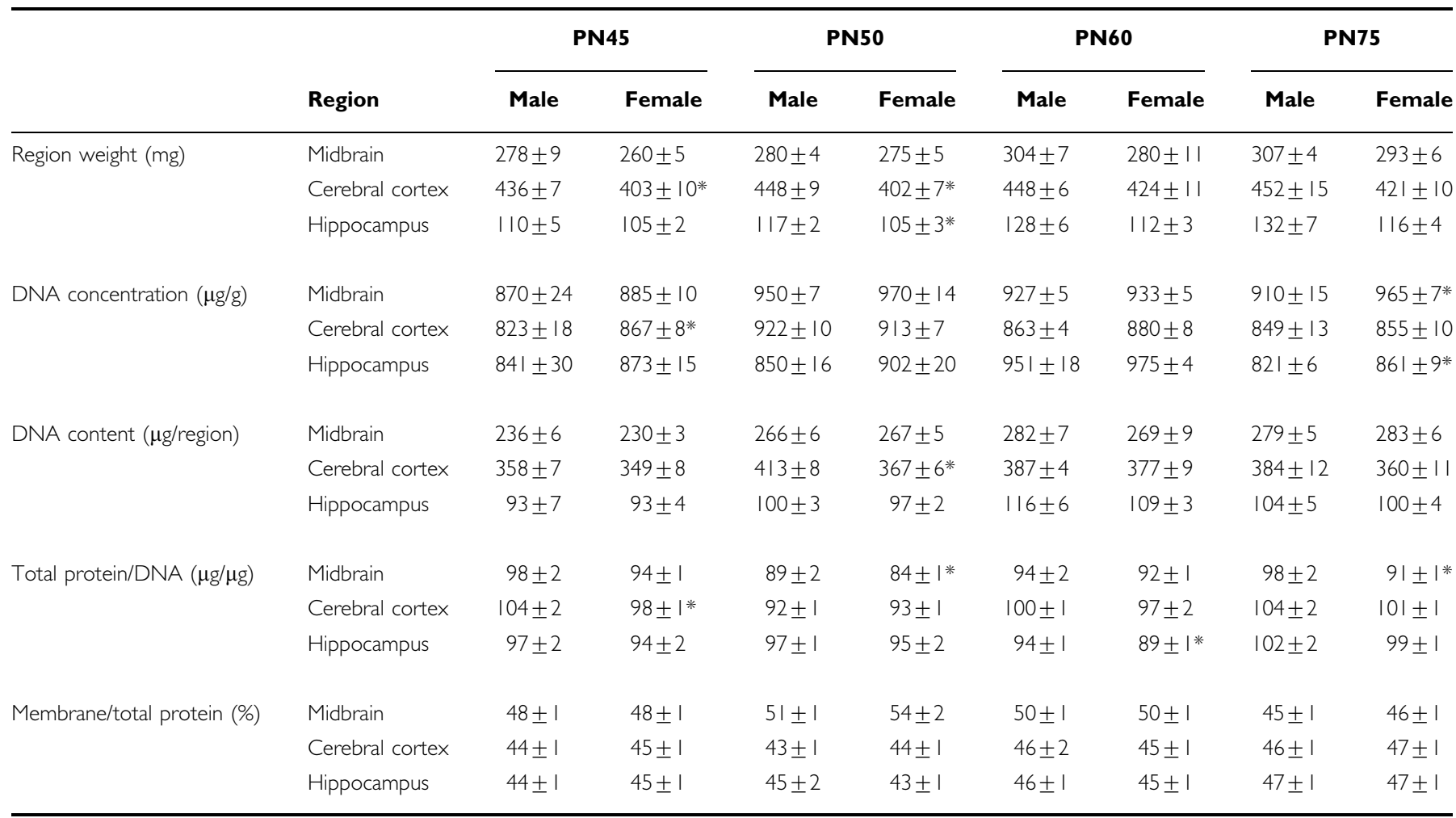

Data represent means and standard errors and * denotes control values for which females differ significantly from males. 
ability of adolescent nicotine treatment to elicit the small decrement in body weight (no interaction of prenatal nicotine $\times$ adolescent nicotine in ANOVA with the twofactor treatment design). For brain region weights (Figure 1), ANOVA across all three regions indicated a main treatment effect $\left(\mathrm{F}_{3,477}=3.6, p<0.02\right)$ reflecting a significant net increase in the group that received the combined treatment $(p<0.009$, FPLSD). The effect of nicotine was interactive with region $\left(\mathrm{F}_{6,477}=2.1, p<0.05\right)$ and age $\left(\mathrm{F}_{9,477}=1.8, p<0.07\right)$, but after separation by brain region, the interactions with age were not maintained; there were no treatment $\times$ sex interactions, so results for both sexes were combined for presentation. Examining the three separate regions, there were no effects in the midbrain (Figure 1a) and cerebral cortex (Figure 2b), but in the hippocampus (Figure 2c), we found an overall increase in region weight (main treatment effect, $\mathrm{F}_{3,159}=5.2, p<0.002$ ) which reached significance in the group that received the combined treatment $(p<0.002$, FPLSD). The effect of combined exposure on hippocampus weights was statistically distinguishable from the smaller effect of adolescent treatment $(p<0.002$, FPLSD), but was not distinguishable from the effect of prenatal nicotine, which was nearly of the same magnitude but somewhat more variable. Twofactor treatment analysis showed a main effect of prenatal nicotine exposure $\left(\mathrm{F}_{1,477}=9.6, \quad p<0.003\right)$ without any interaction of prenatal $\times$ adolescent nicotine, indicative of the statistically equivalent effects of the prenatal exposure regardless of whether animals received vehicle or nicotine in adolescence.

Multivariate ANOVA, combining all contributing variables and all four neurochemical measures, and considering the four treatments in a one-dimensional design, indicated interactions of treatment $\times$ age $\left(\mathrm{F}_{9,1323}=2.0, p<0.04\right)$ and treatment $\times$ measure $\left(\mathrm{F}_{9,1323}=3.4, p<0.0005\right)$, as well as three-factor interactions of treatment $\times$ measure $\times$ age $\left(\mathrm{F}_{27,1323}=1.5, p<0.05\right)$, and treatment $\times$ measure $\times$ region $\left(\mathrm{F}_{18,1323}=3.0, p<0.0001\right)$. With the prenatal and adolescent treatments considered as separate factors in a two-dimensional design, we again found interactions indicative of selective effects on each type of measurement: prenatal treatment $\times$ measure $\left(\mathrm{F}_{3,1323}=3.0, p<0.04\right)$, prenatal treatment $\times$ age $\times$ measure $\quad\left(\mathrm{F}_{9,1323}=1.8, \quad p<0.07\right), \quad$ prenatal treatment $\times$ region $\times$ measure $\quad\left(\mathrm{F}_{6,1323}=6.8, \quad p<0.0001\right)$, prenatal treatment $\times$ age $\times$ region $\times$ measure $\left(\mathrm{F}_{18,1323}=1.7\right.$, $p<0.04)$, adolescent treatment $\times$ measure $\left(\mathrm{F}_{3,1323}=3.2\right.$, $p<0.03)$. In addition, the prenatal treatment interacted with sex (prenatal treatment $\times$ age $\times \operatorname{sex} \times$ measure, $\left.\mathrm{F}_{9,1323}=2.2, \quad p<0.03\right)$, necessitating examination of sex interactions in lower-order analyses. Furthermore, the two treatments interacted with each other, indicating that prenatal nicotine exposure altered the effects of nicotine administered in adolescence and, since these effects were also interactive with age and measure, lower order analyses of treatment effects were required: $p<0.06\left(\mathrm{~F}_{1,1323}=3.8\right)$ for prenatal treatment $\times$ adolescent treatment, $\quad p<0.02$ $\left(\mathrm{F}_{3,1323}=3.7\right)$ for prenatal treatment $\times$ adolescent treatment $\times$ age, $p<0.02 \quad\left(\mathrm{~F}_{3,1323}=3.7\right)$ for prenatal treatment $\times$ adolescent treatment $\times$ measure, and $p<0.06$ $\left(\mathrm{F}_{9,1323}=1.8\right)$ for prenatal treatment $\times$ adolescent treatment $\times$ age $\times$ measure. Given the interaction of each treatment with the type of measurement, we separated the data
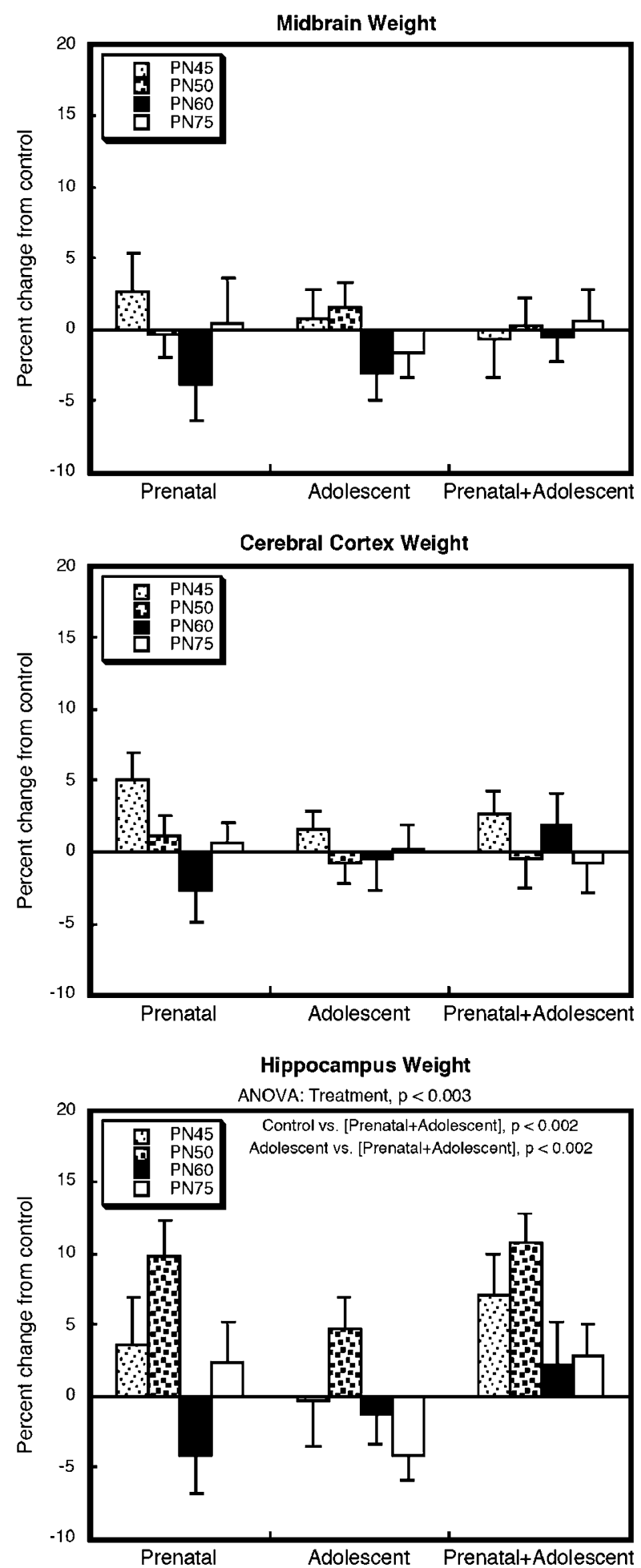

Figure I Effects of adolescent nicotine administration on brain region weights, presented as the percent change from control values (see Table I). Nicotine was administered during gestation (GD4-2I), adolescence (PN30-47), or during both developmental periods. ANOVA across all treatments and ages appears at the top of the panels and intergroup comparisons are shown within the panels. Values were combined for males and females because of the absence of treatment $\times$ sex interactions and tests for individual ages were not carried out because of the lack of treatment $x$ age interactions. 
into the individual measures and then reexamined the results for main effects of nicotine and interactions with the other variables.
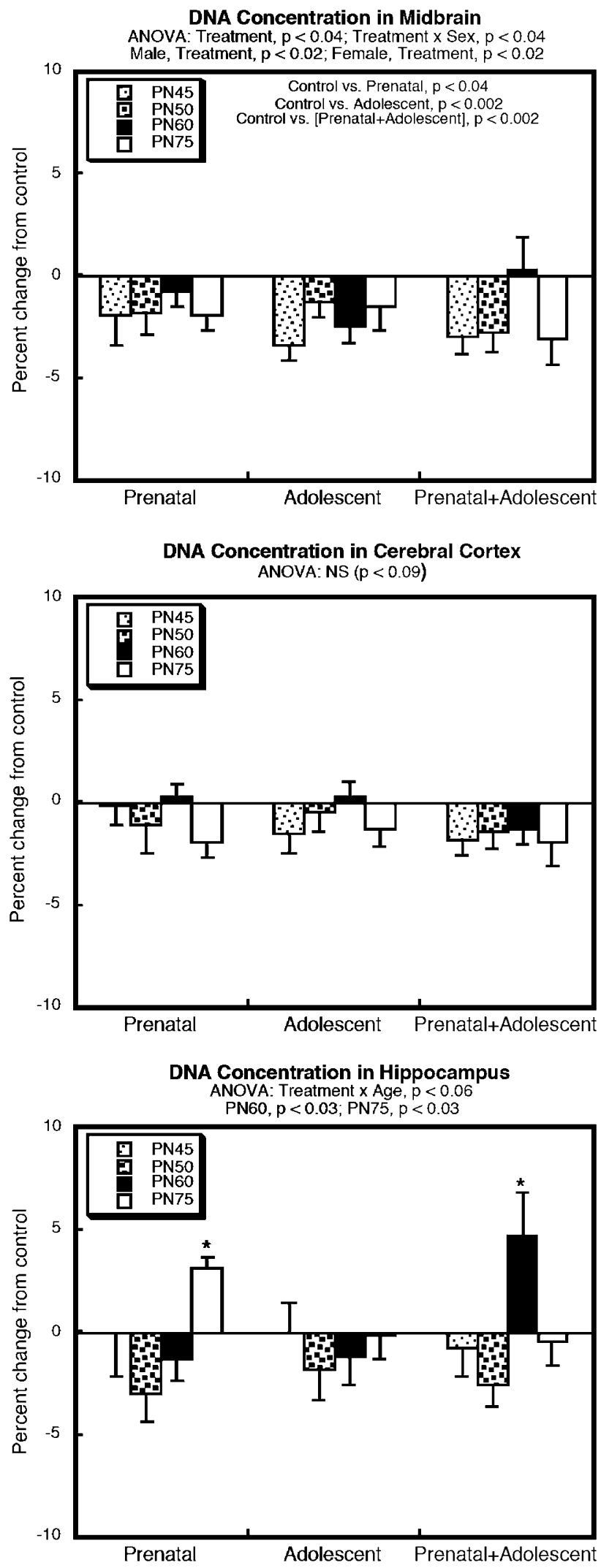

\section{Effects on DNA Concentration (Figure 2)}

Regarding treatment as a one-dimensional variable with four treatment groups, ANOVA across all treatments, regions and ages, and both sexes, indicated a significant main treatment effect $\left(\mathrm{F}_{3,464}=3.4, p<0.02\right)$ but no interactions of treatment with other variables. Each treatment group showed a significant overall decrement (FPLSD) as compared to controls: $p<0.04$ for prenatal nicotine, $p<0.005$ for adolescent nicotine, and $p<0.01$ for the combined treatment. Expanding the analysis to consider the prenatal and adolescent treatments as two separable factors uncovered additional changes: $p<0.02\left(\mathrm{~F}_{1,464}=6.0\right)$ for the main effect of adolescent nicotine, $p<0.08$ $\left(\mathrm{F}_{3,464}=2.3\right)$ for prenatal nicotine $\times$ age, $p<0.1$ $\left(\mathrm{F}_{2,464}=2.3\right)$ for adolescent nicotine $\times$ region $\times$ sex, and $p<0.03 \quad\left(\mathrm{~F}_{1,464}=4.8\right)$ for the interaction of prenatal $\times$ adolescent nicotine $\times$ sex. Accordingly, we looked both for overall effects of the individual treatments as well as for interactive effects within each region.

In the midbrain (Figure 2a), each treatment paradigm elicited a significant overall decrement in the DNA concentration. Although the effect was interactive with sex, both males and females showed significant reductions in DNA. The sex effect reflected a single age point for a single treatment group (combined treatment on PN60) for which a small deficit was present in males $(-3.5 \pm 1.1 \%)$ but not females $(+4.0 \pm 1.9 \%)$; accordingly, the figure shows the effects for both sexes combined. In the cerebral cortex (Figure 2b), the overall effects of the three nicotine treatment paradigms were similar to those seen in the midbrain but somewhat smaller, and thus did not achieve statistical significance $\left(\mathrm{F}_{3,155}=2.3, p<0.09\right)$; indeed, the statistically marginal effects in the cerebral cortex were indistinguishable from the significant deficits seen in the midbrain and, when considered separately, effects in the cerebral cortex of the combined treatment were individually significant $(p<0.02$, FPLSD). There were no differences in nicotine effects on males $v s$ females. The hippocampus (Figure 2c) displayed a complex time course (treatment $\times$ age interaction, $\left.\mathrm{F}_{9,151}=1.9, p<0.06\right)$ with the overall pattern clearly influenced by the denominator term (tissue weight) reflecting the biphasic effect seen for tissue weight. Accordingly, interpretation of hippocampal DNA values required examination of DNA content, which does not reflect tissue weight (see below).

\section{Effects on DNA Content (Figure 3)}

With treatment considered as a one-dimensional variable, ANOVA across all regions and ages detected both a main treatment effect $\left(\mathrm{F}_{3,463}=3.7, p<0.02\right)$ and an interaction of treatment $\times$ region $\left(\mathrm{F}_{6,463}=4.2, p<0.0005\right)$. With the pre-

Figure 2 Effects of adolescent nicotine administration on DNA concentration, presented as the percent change from control values (see Table I). Nicotine was administered during gestation (GD4-2I), adolescence (PN30-47), or during both developmental periods. ANOVA across all treatments and ages appears at the top of the panels and intergroup comparisons are shown within the panels. Tests of individual ages (asterisks) were carried out only where the ANOVA indicated an interaction of treatment $x$ age. 
natal and adolescent treatments considered as two dimensions, we found a significant main effect of prenatal nicotine $\left(\mathrm{F}_{1,463}=6.8, p<0.01\right)$ and interactions of prenatal nicotine $\times$ region $\left(\mathrm{F}_{2,463}=9.3, p<0.0002\right)$, prenatal $\times$ adolescent nicotine $\left(\mathrm{F}_{1,463}=3.7, p<0.06\right)$, and prenatal $\times$ adolescent nicotine $\times$ age $\left(\mathrm{F}_{3,463}=2.6, \quad p<0.06\right)$. In the midbrain (Figure 3a), decreases in DNA content did not reach statistical significance and there was no treatment $\times$ sex interaction, so that values of males and females were combined for presentation. In the cerebral cortex (Figure $3 \mathrm{~b}$ ), the effects of nicotine were dependent on both age and sex (treatment $\times$ age $\times$ sex, $F_{9,155}=2.1, p<0.04$ ), necessitating lower-order analyses for each sex. In males, adolescent nicotine treatment elicited a significant decrease in DNA content in the immediate post-treatment period, with values resolving to normal thereafter. The same effect was seen in males exposed to nicotine prenatally and then given nicotine in adolescence. In females, the primary effect was elicited by prenatal nicotine exposure, which produced a transient increase in DNA content in adolescence regardless of whether animals received adolescent nicotine subsequently. In the hippocampus (Figure 3c), nicotine treatment evoked a significant overall increase in DNA content (main treatment effect, $\mathrm{F}_{3,153}=5.7, p<0.002$ ), again without distinction by sex. For prenatal treatment alone, the effect was more variable and thus was at the margin of significance $(p<0.07$, FPLSD). Adolescent exposure, on the other hand, evoked only minor changes, whereas the combined exposure produced an overall elevation similar to (but more consistent than) that evoked by prenatal nicotine exposure. The lack of significant effect for the group given adolescent nicotine alone was statistically distinguishable from the effects in the prenatal nicotine and combined treatment groups. None of the regions showed a significant interaction of prenatal nicotine $\times$ adolescent nicotine when the two treatments were considered as a two-dimensional variable, indicating that the effects of the combined treatment could not be distinguished statistically from the summation of the effects of the two individual treatments.

\section{Effects on the Ratio of Total Protein/DNA (Figure 4)}

With treatment variables regarded as a single dimension, global ANOVA detected a main treatment effect $\left(\mathrm{F}_{3,467}=4.5, p<0.004\right)$ with significant differences (FPLSD) between control and prenatal nicotine groups $(p<0.04)$, prenatal nicotine and adolescent nicotine groups $(p<0.007)$, and prenatal nicotine and the combined treatment groups $(p<0.0002)$. For consistency, the results are still presented separately for each region (midbrain, Figure 4a; cerebral cortex, Figure 4b; hippocampus, Figure 4c), but any interpretation of regional differences is clouded by the absence of significant treatment $\times$ region interactions. However, the effects were strongly dependent on sex (treatment $\times$ sex interaction, $F_{3,467}=4.2, p<0.006$ ), necessitating separate analyses for males and females. Across all three regions, males showed a significant main treatment effect $\left(\mathrm{F}_{3,231}=2.8, p<0.04\right)$, reflecting a net decrease in total protein/DNA evoked by prenatal nicotine exposure $(p<0.004$, FPLSD), regardless of whether or not the animals received subsequent adolescent nicotine treat-
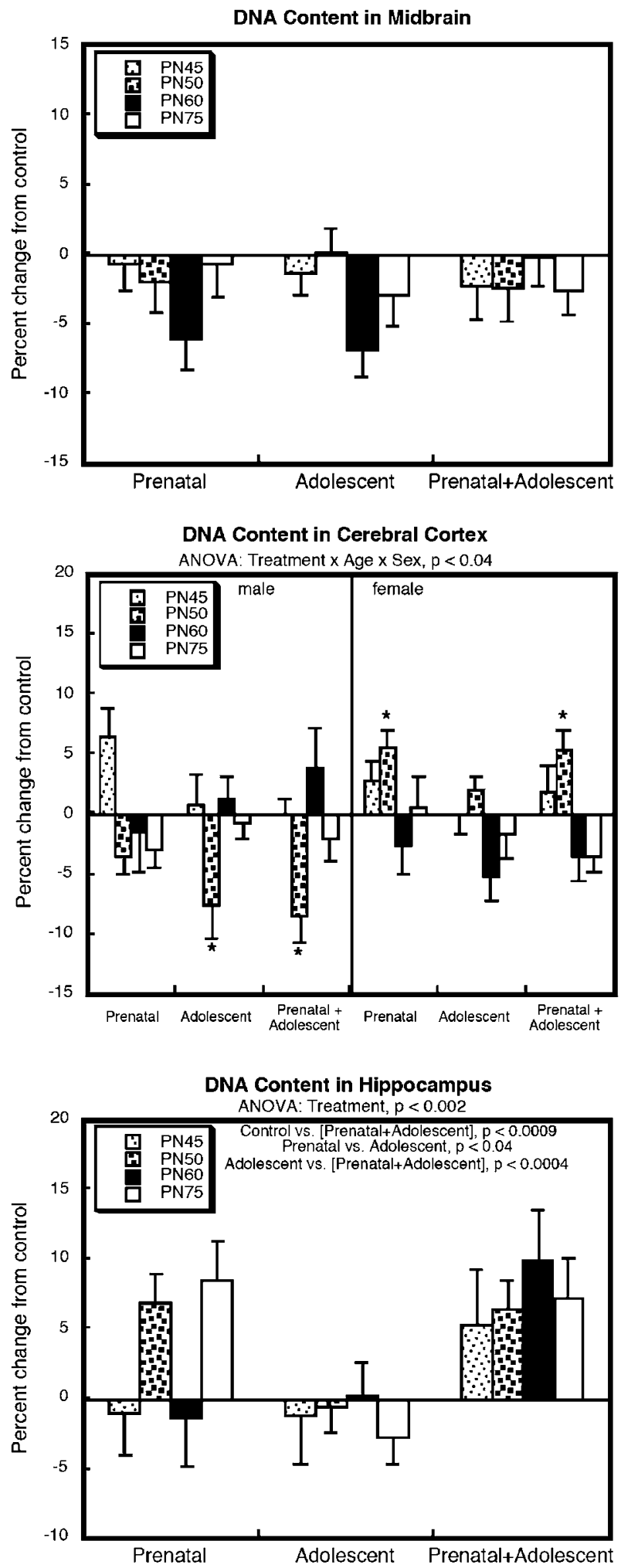

Figure 3 Effects of adolescent nicotine administration on DNA content, presented as the percent change from control values (see Table I). Nicotine was administered during gestation (GD4-2I), adolescence (PN30-47), or during both developmental periods. ANOVA across all treatments and ages appears at the top of the panels and intergroup comparisons are shown within the panels. Tests of individual ages (asterisks) or sexes were carried out only where the ANOVA indicated an interaction of treatment with those variables. 


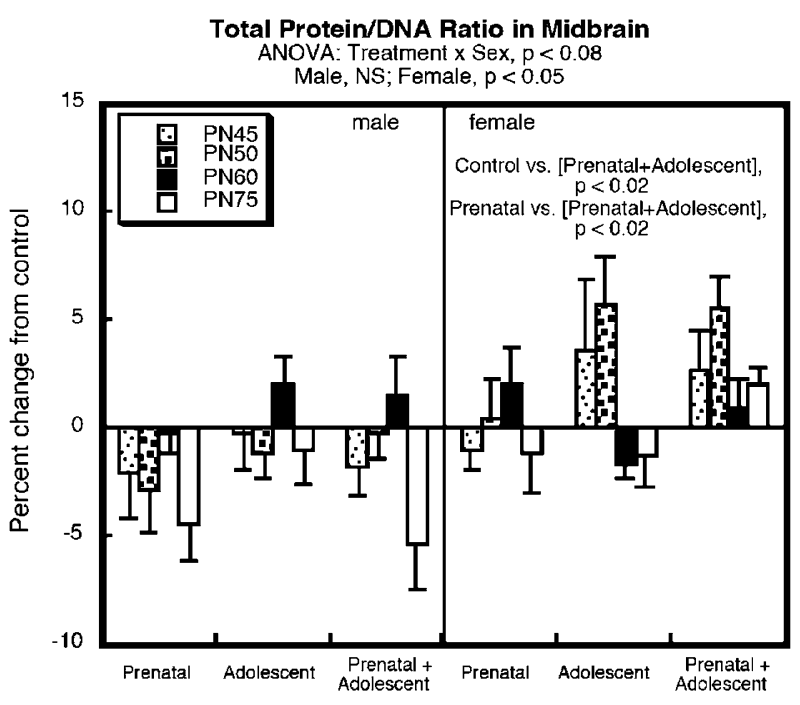

Total Protein/DNA Ratio in Cerebral Cortex

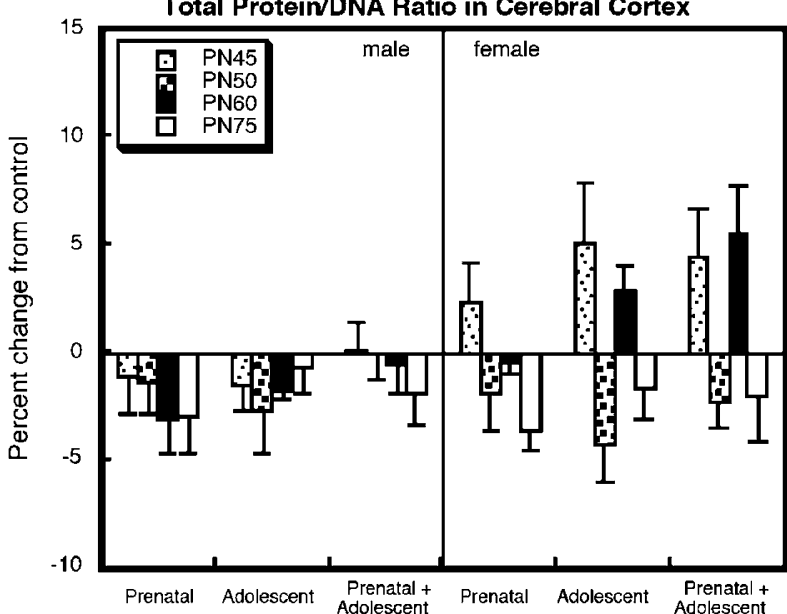

Total Protein/DNA Ratio in Hippocampus ANOVA: Treatment $x$ Sex, $p<0.05$ Male, NS; Female, $p<0.03$

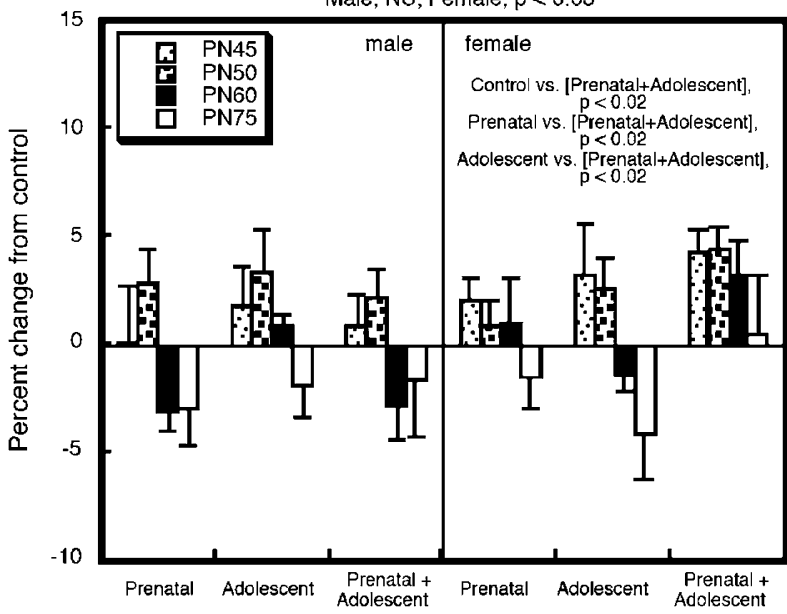

Figure 4 Effects of adolescent nicotine administration on the ratio of total protein to DNA, presented as the percent change from control values (see Table I). Nicotine was administered during gestation (GD4-2I), adolescence (PN30-47) or during both developmental periods. ANOVA across all treatments and ages appears at the top of the panels and intergroup comparisons are shown within the panels. Values were divided into males and females because of the global treatment $x$ sex interaction (see text) but tests of individual ages were not carried out because of the absence of a treatment $x$ age interaction. ment; accordingly, the prenatal exposure was distinguishable from the lesser effect of adolescent nicotine treatment $(p<0.005$, FPLSD) but not from the combined exposure. The effects in males did not achieve significance when each region was considered separately but this should be approached with caution, since there was no treatment $\times$ region interaction to permit separate distinction of regional effects. In females, nicotine had an opposite and larger effect, raising the total protein/DNA ratio. The main treatment effect $\left(\mathrm{F}_{3,236}=5.9, p<0.0001\right)$ involved differences (FPLSD) between the control and adolescent groups $(p<0.0004)$, the prenatal nicotine and combined treatment groups $(p<0.0005)$, and the adolescent nicotine and combined treatment groups $(p<0.02)$. Thus, in this case, adolescent nicotine treatment had greater effects than prenatal exposure.

With treatment considered as a two-dimensional variable, the same interactions were seen: $p<0.003\left(\mathrm{~F}_{1,467}=9.3\right)$ for prenatal nicotine treatment $\times$ sex, and $p<0.08\left(\mathrm{~F}_{1,467}=3.1\right)$ for adolescent nicotine $\times$ sex. In addition, there was a main effect of adolescent nicotine $\left(\mathrm{F}_{1,467}=8.2, p<0.005\right)$ and a significant interaction between the two treatments (prenatal $\times$ adolescent nicotine, $\mathrm{F}_{1,467}=5.2, p<0.03$ ), indicating that prenatal nicotine exposure altered the subsequent effect of nicotine given in adolescence. Although the significant interaction of the two treatments thus indicated that effect of combined prenatal and adolescent treatment could not be statistically accounted for by the summation of the two individual sets of effects, that distinction rested on differences seen in only one region (hippocampus) at one age (PN75) in females, where either treatment alone caused a nonsignificant decrease, whereas the combined treatment produced a nonsignificant increase. All other effects of combined treatment were indistinguishable from simple additivity of the effects of prenatal and adolescent nicotine.

\section{Effects on the Ratio of Membrane/Total Protein (Figure 5)}

With a one-dimensional arrangement of the treatment variables, ANOVA detected interactions of treatment $\times$ age $\left(\mathrm{F}_{9,469}=1.7, \quad p<0.1\right), \quad$ treatment $\times$ region $\quad\left(\mathrm{F}_{6,469}=3.4\right.$, $p<0.003)$, treatment $\times$ age $\times$ region $\left(\mathrm{F}_{18,469}=1.6, p<0.06\right)$, and treatment $\times$ age $\times \operatorname{sex}\left(\mathrm{F}_{9,469}=1.7, p<0.09\right)$. Two-dimensional analysis indicated primary effects of the prenatal treatment: interactions of prenatal nicotine $\times$ region $\left(\mathrm{F}_{2,469}=8.6, \quad p<0.0003\right), \quad$ prenatal nicotine $\times$ age $\left(\mathrm{F}_{3,469}=4.1, \quad p<0.007\right), \quad$ prenatal nicotine $\times$ region $\times$ age $\left(\mathrm{F}_{6,469}=3.6, p<0.002\right)$, and prenatal nicotine $\times$ sex $\times$ age $\left(\mathrm{F}_{3,469}=2.7, p<0.05\right)$. The prenatal treatment also altered the effect of nicotine in adolescence: prenatal $\times$ adolescent nicotine $\left(\mathrm{F}_{1,469}=3.1, p<0.09\right)$, and prenatal $\times$ adolescent nicotine $\times$ region $\times \operatorname{sex}\left(\mathrm{F}_{2,469}=2.8, p<0.07\right)$.

In the midbrain (Figure 5a), there was a treatment $\times$ age interaction $\left(\mathrm{F}_{9,159}=3.2, p<0.002\right)$, requiring consideration of effects at the different age points; since there was no treatment $\times$ sex interaction, values were combined for males and females. Prenatal nicotine exposure evoked a significant overall increase in the membrane/total protein ratio $(p<0.02$, FPLSD $)$ that achieved significance individually at PN45 and PN75. In contrast, adolescent nicotine treatment had little or no effect. The combination of prenatal and 

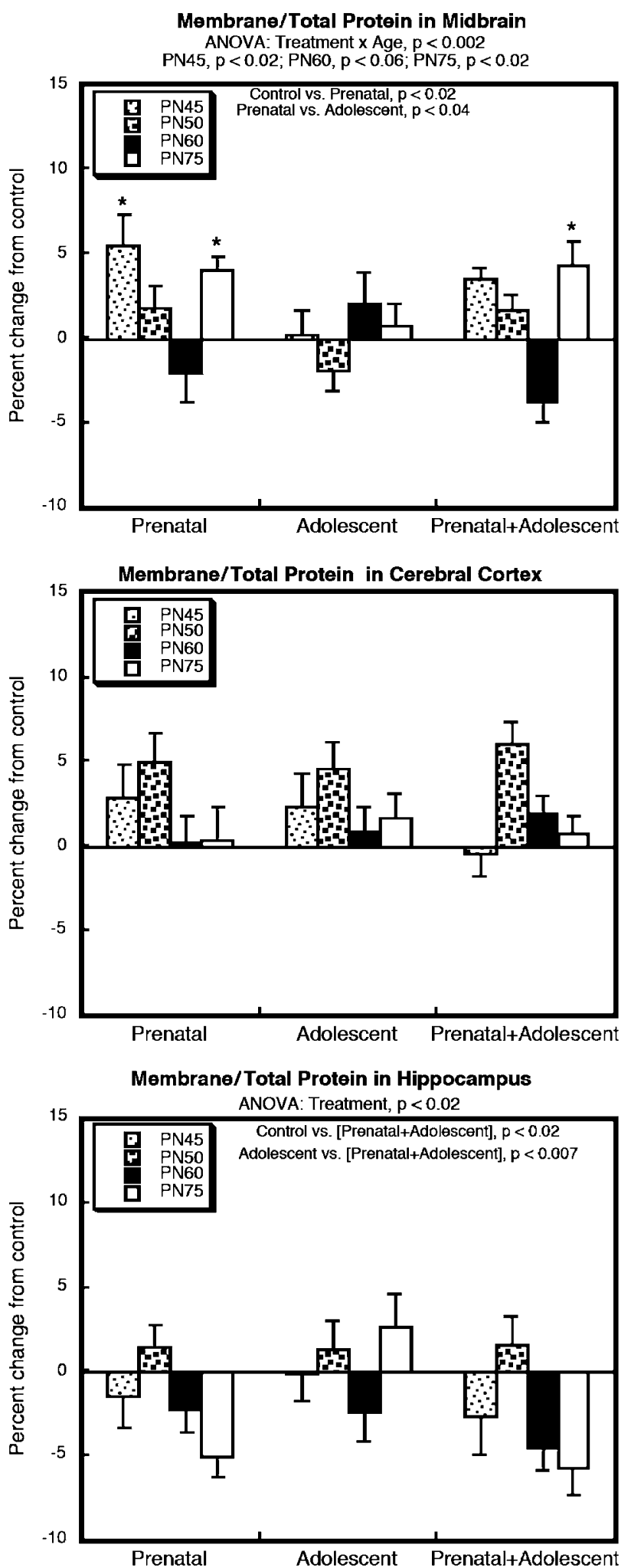

Figure 5 Effects of adolescent nicotine administration on the ratio of membrane to total protein, presented as the percent change from control values (see Table I). Nicotine was administered during gestation (GD42I), adolescence (PN30-47) or during both developmental periods. ANOVA across all treatments and ages appears at the top of the panels and intergroup comparisons are shown within the panels. Asterisks denote individual ages at which the treated groups differ significantly from the corresponding control value, carried out only where the ANOVA indicated an interaction of treatment $\times$ age. adolescent nicotine treatment also showed elevations in membrane/total protein that were indistinguishable from the effects of prenatal exposure alone. In the cerebral cortex (Figure $5 \mathrm{~b}$ ), the effects of nicotine were not significant overall but the lack of significance reflected somewhat higher variability: prenatal nicotine exposure had a similar effect to that seen in the midbrain (no treatment $\times$ region interaction for midbrain and cerebral cortex), and the main effect was significant across the two regions $(p<0.02$, FPLSD). The hippocampus (Figure $5 c$ ) showed an entirely different pattern, characterized by significant decreases evoked by the combination of prenatal and adolescent nicotine treatment, again without distinction by sex. However, the outcome was not distinguishable from simple additivity of the two individually nonsignificant effects of prenatal and adolescent nicotine.

\section{DISCUSSION}

Results obtained in this study indicate that nicotine acts as a developmental neurotoxicant in distinct stages. Prenatal exposure elicits alterations in parameters of cell number, cell size, and membrane surface area that persist into adolescence, thus representing the final outcome of earlier perturbations in patterns of cell acquisition and synaptogenesis during the period of rapid brain development (Levin and Slotkin, 1998; Roy et al, 1998, 2002; Roy and Sabherwal, 1994, 1998; Slotkin, 1992, 1998, 1999). Furthermore, the findings for adolescent treatment by itself, consonant with earlier conclusions (Abreu-Villaça et al, 2003a-c; Slotkin, 2002; Slotkin et al, 2002; Trauth et al, 2000a-c, 2001; Xu et al, 2001, 2002, 2003), indicate that the vulnerability of the brain to nicotine-induced neurotoxicity can be elicited when nicotine is given in adolescence, albeit to a lesser extent than in the fetus. In addition, we found that sequential exposure to prenatal and then adolescent nicotine elicits correspondingly greater damage. In light of epidemiological findings relating maternal smoking during pregnancy with adolescent smoking in the offspring (Cornelius et al, 2000; Kandel et al, 1994; Niaura et al, 2001), these findings suggest that the lasting neurotoxic effects of prenatal nicotine exposure from maternal smoking during pregnancy may worsen the long-term consequences of adolescent smoking, effects that could then contribute to greater likelihood of nicotine dependence or augmented withdrawal effects.

Morphological studies show that prenatal nicotine treatment elicits extensive apoptosis in the brain of the offspring during the exposure period (Berger et al, 1998; Roy et al, 1998) and, despite subsequent recovery and repair, structural anomalies are still present in adolescence (Roy and Sabherwal, 1994; Roy et al, 2002). At the biochemical level, initial deficits in cell number tend to recover or to rise above control levels during the later period associated with gliogenesis, suggesting reactive gliosis in response to neuronal damage (Slotkin et al, 1987), and indeed, elevated numbers of glial cells remain morphologically detectable in the hippocampus and somatosensory cortex at the adolescent stage (Roy et al, 2002). In the present study, we found small but significant DNA decreases in the midbrain after prenatal nicotine exposure, in association with an increase in cell surface-to-volume ratio (elevated membrane/total 
protein ratio), results that are also consistent either with the replacement of neurons by glia or with neuronal loss and expansion of the membrane-rich neuropil; the trend toward decreased cell size (subnormal total protein/DNA ratio) suggests that the former explanation is more likely. It should be noted that, unlike morphological determinations, the biochemical approach taken here combines cell populations from highly affected subregions with unaffected areas, lessening the net magnitude of effect. Nevertheless, the fact that significant differences are still seen in adolescence after prenatal nicotine exposure indicates that future morphological evaluations are warranted to identify more profound alterations in this region, which has not heretofore been evaluated. In the cerebral cortex, we found similar changes but to a smaller degree.

In contrast to the effects of prenatal nicotine exposure in the midbrain, we found an increase in hippocampal DNA content in association with overall hippocampal enlargement, indicative of structural changes over and above reactive gliosis. Indeed, previous morphological studies also revealed a higher neuron packing density in specific hippocampal layers in the adolescent brain after prenatal nicotine exposure (Roy et al, 2002). These results seem puzzling in light of the fact that hippocampal progenitor cells are especially susceptible to nicotine-induced apoptosis (Berger et al, 1998). However, unlike most other brain regions, the hippocampus maintains the ability to generate new neurons into adolescence (McEwen, 1999, 2001) and also undergoes extensive, continuous synaptic, and architectural remodeling (Altman and Bayer, 1990; Bayer, 1983; Bayer et al, 1982; McWilliams and Lynch, 1983). Accordingly, the long-term effects of prenatal nicotine exposure on hippocampal integrity represents the profound initial injury elicited directly by nicotine (Berger et al, 1998; Roy et al, 1998) and the subsequent adaptive rearrangement of hippocampal neuronal populations and synaptic connections. Evidence of rearrangement was also evident from the decrease in membrane/total protein, consistent with a loss of neuropil as suggested in earlier, morphological studies (Roy et al, 2002).

The effects of adolescent nicotine treatment on DNA and protein subfractions have been described previously (Abreu-Villaça et al, 2003c; Trauth et al, 2000b) and the findings presented here are in general agreement with those reports. In the current study, we also evaluated whether prenatal nicotine exposure alters the subsequent susceptibility of the brain to neurotoxicant actions of nicotine administered in adolescence. The combined exposure elicited deficits in midbrain DNA and elevations in hippocampal DNA, along with hippocampal enlargement, the same pattern as that obtained with prenatal nicotine exposure alone, albeit that the dual treatment paradigm tended to elicit greater and more consistent alterations. Statistically, the net effects of combined prenatal and adolescent exposure was not distinguishable from the summation of the two individual effects. A similar picture emerged from the studies of cell protein fractions, with the added feature of sex-dependence showing greater effects in females. To a large extent, the latter feature is likely to represent the component contributed by adolescent nicotine treatment which by itself also targets females to a greater extent (Trauth et al, 2000b, c; Xu et al, 2002, 2003).
The reasons underlying the sex-dependent effects of adolescent nicotine treatment have been outlined previously (Trauth et al, 1999, 2000b, c; Xu et al, 2003): neuronal cell turnover and plasticity, and hence the effects of agents that affect cell replication, differentiation and neurite outgrowth, are responsive to estrogen (Tanapat et al, 1999). Although we found significant interactions between prenatal and adolescent nicotine exposure, with only a few exceptions (eg total protein/DNA ratio in hippocampus on PN75) the alterations in these biomarkers, too, showed additive effects of the two treatments. The incremental effects on cellular biomarkers thus represent a worsened outcome from the dual exposure. It should be noted that, in the animal model of adolescent nicotine exposure used here, the dose of nicotine was selected to elicit plasma levels associated with daily smoking (Trauth et al, 2000b), whereas adolescents may typically begin with occasional or lower use (DiFranza et al, 2000, 2002a, b). Nevertheless, in earlier work, we found essentially similar effects from much lower doses of nicotine, regardless of whether exposure occurred continuously as with the minipump model, or episodically via injections (Abreu-Villaça et al, 2003a,c). Accordingly, the sensitizing effects of prenatal nicotine exposure are likely to be present at the initiation of adolescent smoking.

In sum, our major findings are that: (a) prenatal nicotine exposure produces lasting changes in indices of cell number, cell size, and surface area that persist into adolescence, the period where smoking usually commences; (b) these defects can be elicited to a smaller degree by nicotine treatment in adolescence; and (c) combining the two exposures produces a greater net effect. If similar changes occur in the offspring of women who smoke during pregnancy, they could then contribute to enhanced neurobehavioral effects of nicotine or withdrawal symptoms, increasing the susceptibility to nicotine dependence (Cornelius et al, 2000; DiFranza et al, 2000, 2002a, b; Kandel et al, 1994; Niaura et al, 2001). In that way, neurotoxicant effects of nicotine may then explain, in part, the existence of a vulnerable subpopulation of adolescents who are especially predisposed to nicotine addiction (Cornelius et al, 2000; Kandel et al, 1994; Niaura et al, 2001). The fact that prenatal nicotine exposure by itself elicits widespread, lasting alterations almost certainly contributes to long-term changes involving multiple neurotransmitter systems and circuits throughout the brain (Abreu-Villaça et al, 2003a-c; Levin and Slotkin, 1998; Roy et al, 1998, 2002; Roy and Sabherwal, 1994, 1998; Slotkin, 1992, 1998, 1999, 2002; Slotkin et al, 2002; Trauth et al, 2000a-c, 2001; Xu et al, 2001, 2002, 2003) and thus future studies need to address how these pathways are affected by sequential prenatal and adolescent nicotine exposure; a parallel study from our group has already found similar worsening of outcomes directed toward cholinergic systems (Abreu-Villaça et al, 2004) but, given the more generalized neurotoxicant effects, there is no reason to suspect that the synaptic effects will be limited to acetylcholine. Our findings in rats thus point to specific biological bases for the increased susceptibility of adolescent smokers to nicotine dependence, and particularly the subpopulation of adolescents whose mothers smoked during pregnancy; we suggest that this higher vulnerability comprises components of nicotine neurotoxicity as well as selective alterations in synaptic communication. 


\section{ACKNOWLEDGEMENTS}

This work was supported by a grant and fellowship from the External Research Program of Philip Morris, Inc., and by a fellowship from CNPq Brazil.

\section{REFERENCES}

Abreu-Villaça Y, Seidler FJ, Qiao D, Tate CA, Cousins MM, Thillai I et al (2003a). Short-term adolescent nicotine exposure has immediate and persistent effects on cholinergic systems: critical periods, patterns of exposure, dose thresholds. Neuropsychopharmacology 28: 1935-1949.

Abreu-Villaça Y, Seidler FJ, Slotkin TA (2003b). Impact of adolescent nicotine exposure on adenylyl cyclase-mediated cell signaling: enzyme induction, neurotransmitter-specific effects, regional selectivities, and the role of withdrawal. Brain Res 988: $164-172$

Abreu-Villaça Y, Seidler FJ, Tate CA, Cousins MM, Slotkin TA (2004). Prenatal nicotine exposure alters the response to nicotine administration in adolescence: effects on cholinergic systems during exposure and withdrawal. Neuropsychopharmacology 29: 879-890.

Abreu-Villaça Y, Seidler FJ, Tate CA, Slotkin TA (2003c). Nicotine is a neurotoxin in the adolescent brain: critical periods, patterns of exposure, regional selectivity, and dose thresholds for macromolecular alterations. Brain Res 979: 114-128.

Altman J, Bayer SA (1990). Migration and distribution of two populations of hippocampal granule cell precursors during the perinatal and postnatal periods. J Comp Neurol 301: 365-381.

Bauman KE, Foshee VA, Linzer MA, Koch GG (1990). Effect of parental smoking classification on the association between parental and adolescent smoking. Addict Behav 15: 413-422.

Bayer SA (1983). $\left[{ }^{3} \mathrm{H}\right]$ Thymidine-radiographic studies of neurogenesis in the rat olfactory bulb. Exp Brain Res 50: 329-340.

Bayer SA, Yackel JW, Puri PS (1982). Neurons in the rat dentate gyrus granular layer substantially increase during juvenile and adult life. Science 216: 890-892.

Bell JM, Whitmore WL, Queen KL, Orband-Miller L, Slotkin TA (1987). Biochemical determinants of growth sparing during neonatal nutritional deprivation or enhancement: ornithine decarboxylase, polyamines, and macromolecules in brain regions and heart. Pediatr Res 22: 599-604.

Berger F, Gage FH, Vijayaraghavan S (1998). Nicotinic receptorinduced apoptotic cell death of hippocampal progenitor cells. J Neurosci 18: 6871-6881.

Centers for Disease Control and Prevention (1998). Tobacco use among high school students-United States, 1997. Morbid Mortal Wkly Rep 47: 229-233.

Chassin L, Presson CC, Rose JS, Sherman SJ, Prost J (2002). Parental smoking cessation and adolescent smoking. J Pediatr Psychol 27: 495-496.

Cheeta S, Irvine EE, Tucci S, Sandhu J, File SE (2001). In adolescence, female rats are more sensitive to the anxiolytic effect of nicotine than are male rats. Neuropsychopharmacology 25: 601-607.

Cornelius MD, Leech SL, Goldschmidt L, Day NL (2000). Prenatal tobacco exposure: is it a risk factor for early tobacco experimentation? Nicotine Tobacco Res 2: 45-52.

DiFranza J, Savageau JA, Rigotti NA, Fletcher K, Ockene JK, McNeill AD et al (2002a). Development of symptoms of tobacco dependence in youths: 30-month follow-up data from the DANDY study. Tobacco Control 11: 228-235.

DiFranza JR, Rigotti NA, McNeill AD, Ockene JK, Savageau JA, St. Cyr D et al (2000). Initial symptoms of nicotine dependence in adolescents. Tobacco Control 9: 313-319.

DiFranza JR, Savageau JA, Fletcher K, Ockene JK, Rigotti NA, McNeill AD et al (2002b). Measuring the loss of autonomy over nicotine use in adolescents: the DANDY (development and assessment of nicotine dependence in youths) study. Arch Pediatr Adolesc Med 156: 397-403.

Faraday MM, Elliott BM, Grunberg NE (2001). Adult $v s$ adolescent rats differ in biobehavioral responses to chronic nicotine administration. Pharmacol Biochem Behav 70: 475-489.

Isaac PF, Rand MJ (1972). Cigarette smoking and plasma levels of nicotine. Nature 236: 308-310.

Kandel DB, Wu P, Davies M (1994). Maternal smoking during pregnancy and smoking by adolescent daughters. Am J Public Health 84: 1407-1413.

Kelley BM, Middaugh LD (1999). Periadolescent nicotine exposure reduces cocaine reward in adult mice. J Addict Dis 18: 27-39.

Klein LC (2001). Effects of adolescent nicotine exposure on opioid consumption and neuroendocrine responses in adult male and female rats. Exp Clin Psychopharmacol 9: 251-261.

Labarca C, Piagen K (1980). A simple, rapid, and sensitive DNA assay procedure. Anal Biochem 102: 344-352.

Levin ED, Slotkin TA (1998). Developmental neurotoxicity of nicotine. In: Slikker W, Chang LW (eds). Handbook of Developmental Neurotoxicology. Academic Press: San Diego. pp 587-615.

Lichtensteiger W, Ribary U, Schlumpf M, Odermatt B, Widmer HR (1988). Prenatal adverse effects of nicotine on the developing brain. Prog Brain Res 73: 137-157.

Luck W, Nau H, Hansen R, Steldinger R (1985). Extent of nicotine and cotinine transfer to the human fetus, placenta and amniotic fluid of smoking mothers. Dev Pharmacol Ther 8: 384-395.

McEwen BS (1999). Stress and hippocampal plasticity. Annu Rev Neurosci 22: 105-122.

McEwen BS (2001). Plasticity of the hippocampus: adaptation to chronic stress and allostatic load. Annals NY Acad Sci 933: 265-277.

McWilliams JR, Lynch G (1983). Rate of synaptic replacement in denervated rat hippocampus declines precipitously from the juvenile period to adulthood. Science 221: 572-574.

Murrin LC, Ferrer JR, Zeng W (1985). Nicotine administration during pregnancy and its effect on striatal development. Neurosci Abstr 11: 69.

National Institute on Drug Abuse (1998). Nicotine Addiction, NIH Publication Number 98-4342, National Institute on Drug Abuse: Washington, DC, 7pp.

Nelson DE, Giovino GA, Shopland DR, Mowery PD, Mills SL, Eriksen MP (1995). Trends in cigarette smoking among US adolescents, 1974 through 1991. Am J Public Health 85: 34-40.

Niaura R, Bock B, Lloyd EE, Brown R, Lipsitt LP, Buka S (2001). Maternal transmission of nicotine dependence: psychiatric, neurocognitive and prenatal factors. Am J Addict 10: 16-29.

Pierce JP, Gilpin E (1996). How long will today's new adolescent smoker be addicted to cigarettes? Am J Public Health 86: 253-256.

Ribary U, Lichtensteiger W (1989). Effects of acute and chronic prenatal nicotine treatment on central catecholamine systems of male and female rat fetuses and offspring. J Pharmacol Exp Ther 248: 786-792.

Roy TS, Andrews JE, Seidler FJ, Slotkin TA (1998). Nicotine evokes cell death in embryonic rat brain during neurulation. J Pharmacol Exp Ther 287: 1135-1144.

Roy TS, Sabherwal U (1994). Effects of prenatal nicotine exposure on the morphogenesis of somatosensory cortex. Neurotoxicol Teratol 16: 411-421.

Roy TS, Sabherwal U (1998). Effects of gestational nicotine exposure on hippocampal morphology. Neurotoxicol Teratol 20: $465-473$

Roy TS, Seidler FJ, Slotkin TA (2002). Prenatal nicotine exposure evokes alterations of cell structure in hippocampus and somatosensory cortex. J Pharmacol Exp Ther 300: 124-133.

Sarasin A, Schlumpf M, Müller M, Fleischmann I, Lauber ME, Lichtensteiger W (2003). Adrenal-mediated rather than direct 
effects of nicotine as a basis of altered sex steroid synthesis in fetal and neonatal rat. Reprod Toxicol 17: 153-162.

Slawecki CJ, Ehlers CL (2002). Lasting effects of adolescent nicotine exposure on the electroencephalogram, event related potentials, and locomotor activity in the rat. Dev Brain Res 138: $15-25$.

Slotkin TA (1992). Prenatal exposure to nicotine: What can we learn from animal models?. In: Zagon IS, Slotkin TA (eds). Maternal Substance Abuse and the Developing Nervous System. Academic Press: San Diego. pp 97-124.

Slotkin TA (1998). Fetal nicotine or cocaine exposure: which one is worse? J Pharmacol Exp Ther 285: 931-945.

Slotkin TA (1999). Developmental cholinotoxicants: nicotine and chlorpyrifos. Environ Health Perspect 107(Suppl 1): 71-80.

Slotkin TA (2002). Nicotine and the adolescent brain: insights from an animal model. Neurotoxicol Teratol 24: 369-384.

Slotkin TA (2004). Cholinergic systems in brain development and disruption by neurotoxicants: nicotine, environmental tobacco smoke, organophosphates. Toxicol Appl Pharmacol, in press.

Slotkin TA, Orband-Miller L, Queen KL, Whitmore WL, Seidler FJ (1987). Effects of prenatal nicotine exposure on biochemical development of rat brain regions: maternal drug infusions via osmotic minipumps. J Pharmacol Exp Ther 240: 602-611.

Slotkin TA, Persons D, Slepetis RJ, Taylor D, Bartolome J (1984). Control of nucleic acid and protein synthesis in developing brain, kidney, and heart of the neonatal rat: effects of $\alpha$ difluoromethylornithine, a specific, irreversible inhibitor of ornithine decarboxylase. Teratology 30: 211-224.

Slotkin TA, Tate CA, Cousins MM, Seidler FJ (2002). Functional alterations in CNS catecholamine systems in adolescence and adulthood after neonatal chlorpyrifos exposure. Dev Brain Res 133: 163-173.

Smith PK, Krohn RI, Hermanson GT, Mallia AK, Gartner FH, Provenzano MD et al (1985). Measurement of protein using bicinchoninic acid. Anal Biochem 150: 76-85.

Snedecor GW, Cochran WG (1967). Statistical Methods. Iowa State University Press: Ames, Iowa. 593pp.
Spear LP (2000). The adolescent brain and age-related behavioral manifestations. Neurosci Biobehav Rev 24: 417-463.

Tanapat P, Hastings NB, Reeves AJ, Gould E (1999). Estrogen stimulates a transient increase in the number of new neurons in the dentate gyrus of the adult female rat. $J$ Neurosci 19: 5792-5801.

Trauth JA, McCook EC, Seidler FJ, Slotkin TA (2000a). Modeling adolescent nicotine exposure: effects on cholinergic systems in rat brain regions. Brain Res 873: 18-25.

Trauth JA, Seidler FJ, Ali SF, Slotkin TA (2001). Adolescent nicotine exposure produces immediate and long-term changes in CNS noradrenergic and dopaminergic function. Brain Res 892: 269-280.

Trauth JA, Seidler FJ, McCook EC, Slotkin TA (1999). Adolescent nicotine exposure causes persistent upregulation of nicotinic cholinergic receptors in rat brain regions. Brain Res 851: 9-19.

Trauth JA, Seidler FJ, Slotkin TA (2000b). An animal model of adolescent nicotine exposure: effects on gene expression and macromolecular constituents in rat brain regions. Brain Res 867: 29-39.

Trauth JA, Seidler FJ, Slotkin TA (2000c). Persistent and delayed behavioral changes after nicotine treatment in adolescent rats. Brain Res 880: 167-172.

Winick M, Noble A (1965). Quantitative changes in DNA, RNA and protein during prenatal and postnatal growth in the rat. Dev Biol 12: 451-466.

Xu Z, Seidler FJ, Ali SF, Slikker W, Slotkin TA (2001). Fetal and adolescent nicotine administration: effects on CNS serotonergic systems. Brain Res 914: 166-178.

$\mathrm{Xu}$ Z, Seidler FJ, Cousins MM, Slikker W, Slotkin TA (2002). Adolescent nicotine administration alters serotonin receptors and cell signaling mediated through adenylyl cyclase. Brain Res 951: 280-292.

Xu Z, Seidler FJ, Tate CA, Garcia SJ, Slikker W, Slotkin TA (2003). Sex-selective hippocampal alterations after adolescent nicotine administration: effects on neurospecific proteins. Nicotine Tobacco Res 5: 955-960. 